\title{
Canadian Urological Association/Genitourinary Medical Oncologists of Canada consensus statement: Management of unresectable locally advanced and metastatic urothelial carcinoma
}

Mark Warren, MBBS, FRACP ${ }^{1,2}$; Michael Kolinsky, MD, FRCPC ${ }^{1,3}$; Christina M. Canil, MD, FRCPC $^{4,5}$; Piotr Czaykowski, MD, MSc, FRCPC ${ }^{6,7}$; Srikala S. Sridhar, MD,FRCPC ${ }^{8}$; Peter C. Black, MD, FRCSC, FACS ${ }^{9}$; Christopher M. Booth, MD, FRCPC ${ }^{10}$; Wassim Kassouf, MD, CM, FRCSC $^{11}$; Libni Eapen, MD, FRCPC ${ }^{5,12}$; Som D. Mukherjee, MD, MSc, FRCPC ${ }^{13}$; Normand Blais, MD, MSc, FRCPC ${ }^{14}$; Bernhard J. Eigl, MD, FRCPC ${ }^{15}$; Eric Winquist, MD, MSc ${ }^{16}$; Naveen S. Basappa, MD, FRCPC ${ }^{1,3}$; Scott A. North, MD, FRCPC ${ }^{1,3}$; on behalf of GUMOC ${ }^{1}$ Department of Medical Oncology, Cross Cancer Institute, Edmonton, AB, Canada; ${ }^{2}$ Cancer Centre, Bendigo Health, Bendigo, Australia; ${ }^{3}$ University of Alberta, Edmonton, AB, Canada; ${ }^{4}$ The Ottawa Hospital Cancer Centre, Ottawa, ON Canada; ${ }^{5}$ Ottawa Hospital Research Institute, Ottawa, ON, Canada; ${ }^{6}$ Cancer Care Manitoba, Winnipeg, MB, Canada; ${ }^{7}$ University of Manitoba, Winnipeg, MB, Canada; ${ }^{8}$ Division of Hematology and Medical Oncology, Princess Margaret Cancer Centre, University Health Network, University of Toronto, Toronto, ON, Canada; ${ }^{9}$ Department of Urological Sciences, University of British Columbia, Vancouver, BC, Canada; ${ }^{10}$ Department of Oncology, Queen’s University, Kingston, ON, Canada; ${ }^{11}$ Department of Surgery, McGill University Health Centre, Montreal, QC, Canada; ${ }^{12}$ Division of Radiation Oncology, University of Ottawa, ON, Canada; ${ }^{13}$ Juravinski Cancer Centre, Hamilton, ON, Canada; ${ }^{14}$ Division of Medical Oncology/Hematology, Centre Hospitalier de l' Université de Montréal, , Montréal, Quebec, Canada; ${ }^{15}$ BC Cancer, Vancouver, BC, Canada, University of British Columbia, BC, Canada; ${ }^{16}$ Division of Medical Oncology, Western University and London Health Sciences Centre, London, ON, Canada

Cite as: Can Urol Assoc J 2019 April 26; Epub ahead of print. http://dx.doi.org/10.5489/cuaj.6015

Published online April 26, 2019

$* * *$

\section{Introduction}

In Canada, bladder cancer ranks as the $5^{\text {th }}$ most common cancer with an estimated 8900 new cases and 2400 deaths in 2018. ${ }^{1}$ Approximately 15\% of patients have locally advanced or metastatic disease at presentation. A further $40-50 \%$ of those with muscle invasive early stage disease will relapse after initial treatment. The majority of patients with advanced stage disease will succumb to their disease. Cancers of the ureter, renal pelvis and proximal urethra constitute approximately $5-10 \%$ of cases of urothelial carcinoma and are treated with similar systemic therapy as bladder cancer.

GUMOC (Genitourinary Medical Oncologists of Canada) is comprised of Canadian Medical Oncologists who specialize in the treatment of genitourinary cancers. With recent 
advances in systemic therapy, especially due to the emergence of immunotherapy as a therapeutic option, a consensus opinion has become necessary to guide the management of unresectable locally advanced and metastatic urothelial carcinoma.

\section{Methods}

A literature review was undertaken evaluating studies of unresectable locally advanced and metastatic urothelial carcinoma with a greater emphasis on prospective randomized studies. A search of Medline, Embase and Pubmed in addition to other published guidelines was used to identify relevant studies. A summary of the evidence was created with draft recommendations pertaining to various aspects of the management of advanced urothelial carcinoma. This was distributed to members of GUMOC for review and discussion through which a consensus opinion was established.

The following statements focus predominantly on systemic management which falls in the realm of the Medical Oncology specialty. Additionally, the management of advanced, unresectable urothelial cancer is multidisciplinary in nature as there are times when surgery and / or radiotherapy have a role to play, particularly in patients with oligometastatic disease and those with locally advanced disease. In this consensus statement, we define locally advanced disease as cT4b and / or cN1-3. Statements pertaining to these aspects of management are intended to provide guidance for treating clinicians as to when to consider referral for multidisciplinary discussion. They are not intended to mandate a particular management plan that arises from such a forum. All recommended systemic treatment regimens are outlined in Table 1.

Systemic therapy for unresectable locally advanced and metastatic urothelial carcinoma

\section{Eligibility for cisplatin-based chemotherapy}

- Routine eligibility for cisplatin chemotherapy includes all of: (1) creatinine clearance $\geq 60 \mathrm{ml} / \mathrm{min}$, (2) ECOG performance status of $\leq 1$, (3) absence of hearing loss $\geq$ Gr 2 (CTCAE), (4) absence of neuropathy $\geq$ Gr 2 (CTCAE), and (5) absence of NYHA grade III / IV heart failure.

- In select cases, eligibility criteria may be extended to patients with GFR of 45 60mls/min and / or ECOG 2 performance status. Administering split dose cisplatin is an option for these patients.

A consensus definition of eligibility for cisplatin chemotherapy was developed by members of a working party, who combined the results of a survey of 120 medical oncologists involved in research of urothelial carcinoma with an evaluation of the available literature on this topic. The purpose was to develop a consistent definition for clinical trial eligibility. The criteria generated were good performance status (ECOG 0 -1); GFR $>60 \mathrm{mls} / \mathrm{min}$, and absence of contra-indications to cisplatin such as grade $\geq 2$ neuropathy, grade $\geq 2$ hearing loss and NYHA grade III/IV heart failure. ${ }^{2}$ Several studies have used split dose cisplatin to patients with a GFR 


\section{Unresectable locally advanced and metastatic urothelial carcinoma}

as low as $35-40 \mathrm{mls}$ / min and reported acceptable safety outcomes. ${ }^{3,4}$ In practice, cisplatin is rarely used in patients with a GFR $<45 \mathrm{mls} / \mathrm{min}$.

First-line systemic therapy

1. Patient eligible for cisplatin-based chemotherapy:

- In patients suitable for cisplatin based chemotherapy, the preferred routine regimen is gemcitabine / cisplatin (GC).

- Dose dense methotrexate, vinblastine, doxorubicin and cisplatin (DDMVAC) with growth factor support may be considered in select cases where a more aggressive treatment approach is being considered.

Gemcitabine/cisplatin was compared to the earlier standard of methotrexate, vinblastine, doxorubicin and cyclophosphamide (MVAC) in a phase III randomized trial. GC demonstrated similar efficacy but with reduced toxicity. In an updated analysis with a minimum of 5 years of follow up, median overall survival (OS) was 14 months in the GC arm, with a 13\% 5 year survival rate, which was not significantly different from the MVAC arm. The hazard ratio of GC compared to MVAC was 1.09 (95\% CI $0.88-1.34$; $\mathrm{P}=0.66){ }^{5}$ Toxicity was increased in the MVAC arm with a higher rate of grade 3-4 neutropenic sepsis (12\% vs $1 \%$ ), mucositis (22\% vs $1 \%$ ) and toxic death (3\% vs $1 \%)^{6}$

The small proportion of long-term survivors is seen predominantly in patients with good performance status (ECOG $0-1, \mathrm{KFS} \geq 80$ ) and in those patients without visceral metastases (bone, lung, liver). ${ }^{5,7}$ Further attempts have been made to improve on these results by intensifying doses and adding additional chemotherapy agents. One notable regimen is DDMVAC tested in the phase III EORTC 30924 study. This regimen consists of two weekly MVAC with growth factor support and was compared to standard MVAC. Seven year follow up demonstrated a statistically borderline improvement in overall survival with a 5 year OS of 21.8\% in DD-MVAC treated patients compared to $13.5 \%$ with standard MVAC. The hazard ratio of DD-MVAC compared to standard MVAC was 0.76 (95\% CI $0.58-0.99, \mathrm{P}=0.042)$. A compete response (CR) was seen in $21 \%$ of those receiving DD-MVAC compared with $9 \%$ of those receiving standard dose MVAC. The addition of growth factor support reduced neutropenic complications and mucositis in the DD-MVAC arm compared with the standard MVAC arm, however there was still one death due to toxicity in each treatment arm. ${ }^{8}$

Evidence for other regimens is not sufficiently robust to endorse their inclusion as recommended treatments. Dose dense GC (DD-GC) was compared to the DD-MVAC regimen in a phase III study performed by the Hellenic Oncology group. Although DD-GC demonstrated similar efficacy to DD-MVAC with reduced toxicity, the study was underpowered with imbalances in the treatment arms. ${ }^{9}$ Concerns regarding vascular toxicity with this regimen were raised as a result of a neoadjuvant study of DD-GC for muscle invasive bladder cancer in which $23 \%$ of patients experienced grade 3-4 venous and arterial events. ${ }^{10}$ The addition of paclitaxel to GC (PGC) was tested in the phase III EORTC Intergroup 30987 study consisting of 626 patients. 
There was a non-significant 3.2 month median OS improvement favoring PGC in the intention-to-treat (ITT) patient population which reached statistical significance when 47 patients not meeting the eligibility criteria were excluded. An unplanned subgroup analysis revealed benefit in the $81 \%$ of patients with bladder primary. Febrile neutropenia was increased in the PGC arm at $13.2 \%$ compared to $4.3 \% .^{11}$

Currently, there are no completed clinical trials supporting the use of first line immunotherapy in cisplatin eligible patients. However, numerous trials are currently evaluating the role of first line immunotherapy (table 5).

\section{Patient ineligible for cisplatin-based chemotherapy}

- In patients ineligible for cisplatin-based chemotherapy, the preferred regimen is gemcitabine / carboplatin (GCa)

- In patients not suitable for combination chemotherapy, single agent gemcitabine, paclitaxel or docetaxel is recommended.

- Immunotherapy is not routinely recommended in the first line setting for cisplatin-ineligible patients.

Chemotherapy in cisplatin-ineligible patients

Carboplatin based regimens are inferior to cisplatin-based regimens with lower response rates and trend towards inferior survival. ${ }^{12}$. Nonetheless, carboplatin is active in urothelial carcinoma and is the cornerstone of preferred regimens in cisplatin-ineligible patients. Gemcitabine / carboplatin (GCa) was compared to M-CAVI (methotrexate, carboplatin, vinblastine) in the phase III EORTC 30986 study. The population studied was ineligible for cisplatin on the basis of a GFR of $30-60 \mathrm{mls} / \mathrm{min}$ (55\% of patients), WHO PS of 2 (17.6\%) or both (27.3\%). Visceral metastases were present in $51 \%$ of patients. Efficacy was similar in both regimens with a median OS of 9.3 months for GCa and 8.1 months with M-CAVI. Only 8\% of patients were still alive after a median follow up of 4.5 years. Toxicity was reduced with GCa compared to M-CAVI with $9 \%$ cases of severe acute toxicity (SAT) and 2 toxic deaths compared to $21 \%$ cases of SAT and 4 toxic deaths, respectively. ${ }^{13}$ Gemcitabine / carboplatin has thus become the preferred regimen in this generally less robust group of patients.

Several other carboplatin and non carboplatin based regimens have been evaluated in phase II studies. Although demonstrating encouraging results, none of these regimens has been further assessed in phase III studies and are not considered standard regimens. ${ }^{14-21}$ Paclitaxel and gemcitabine has demonstrated overall response rates of between 37 - 70\%, however pulmonary toxicity has been noted. ${ }^{19}$

In patients not suitable for combination therapy, single agent gemcitabine, paclitaxel or docetaxel has been studied in small single arm phase II studies. ${ }^{2-25}$ Response rates have varied between 25 - 47\% but have generally been of short duration with median OS ranging between 8 -12 months in these series. 
Immunotherapy in cisplatin-ineligible patients

Checkpoint inhibitors active on the PD-1 / PD-L1 interaction between tumour cells and cytotoxic $T$ cells, have demonstrated efficacy in a first line setting in cisplatin-ineligible patients with advanced UC. Pembrolizumab, a monoclonal antibody against the PD-1 receptor on T cells and other immune cells, was evaluated in 370 cisplatin-ineligible patients with advanced urothelial carcinoma in a single arm phase II study. An ORR of $29 \%$ was in the range of that seen with chemotherapy, with a potential advantage over chemotherapy existing in both the durability of responses and overall tolerability of this regimen. Sixty eight percent of responses were ongoing at 12 months and grade 3-4 toxicity mostly from immune-related adverse events (irAEs) was seen in 16\% (Table 2). Median OS was 11.5 months. Responses were more likely in patients with PD-L1 positivity on immunohistochemistry (IHC) as measured by a combined positive score (CPS) $\geq 10 \% .{ }^{26,27}$ Similar outcomes were obtained with atezolizumab which is a monoclonal antibody against the PD-L1 receptor on tumour and immune cells. In a single arm, phase II study in 119 patients, the ORR was 23\% with $70 \%$ of responses ongoing after a median follow up of 17.2 months and a median OS of 15.9 months. Grade 3 / 4 toxicity was seen in 16\% of patients. The differential effect of PD-L1 expression by IHC on ORR\% was not as obvious (Table 2). ${ }^{28}$ GUMOC currently does not endorse these agents for first line therapy. This is discussed below in 'Current approvals and status of the evidence of immunotherapy in advanced UC'.

\section{Second-line systemic therapy:}

- In patients who have progressive disease during or after platinum-based chemotherapy, pembrolizumab is the preferred regimen (if available)

- Where pembrolizumab is unavailable or a patient is ineligible, single agent paclitaxel or docetaxel is preferred for the majority of patients.

- Re-treatment with a platinum based regimen is a reasonable option in a patient who has disease progression following a prolonged (> 6 - 12 month) initial response to platinum-based chemotherapy.

\section{Chemotherapy}

Prior to the advent of checkpoint inhibitors in unresectable locally advanced and metastatic UC, there was no standout salvage chemotherapy regimen for patients progressing during or after platinum-based regimens. Re-treatment with a platinum regimen can be a successful strategy in patients with an initial response lasting greater than 6-12 months. ${ }^{29-31}$ Patients progressing within this timeframe are likely to be refractory to further platinum therapy. The only randomized phase III study in this group of patients compared vinflunine to best supportive care. Although OS was not improved in the ITT population, analysis of those patients fulfilling eligibility criteria revealed a median OS benefit of 2 months. ${ }^{32}$ Vinflunine is not available in North America. Although doublet chemotherapy regimens are associated with higher response 
rates, their greater toxicity combined with failure to impact meaningfully on OS has limited their use. ${ }^{33}$ Despite low response rates of approximately $10 \%$, paclitaxel and docetaxel are well tolerated and have emerged as preferred regimens. ${ }^{34-36}$ NAB-paclitaxel has demonstrated efficacy in the second line setting and is a reasonable alternative. ${ }^{37}$

\section{Immunotherapy: Checkpoint inhibitors}

The evidence supporting the use of checkpoint inhibitors in the second line setting is more robust than in the first line setting. Five checkpoint inhibitors have been tested in this setting including 2 in randomized phase III studies.

Pembrolizumab was compared to investigators' choice of single agent paclitaxel, docetaxel or vinflunine in 542 patients with progressive disease during or after platinum based chemotherapy in the randomized phase III Keynote 045 study. Overall response rate was $21 \%$ in the pembrolizumab-treated patients compared with $11 \%$ in chemotherapy-treated patients. Median PFS was only 2.1 months on pembrolizumab compared with 3.3 months on chemotherapy (HR $0.98,95 \%$ CI $0.81-1.19, \mathrm{P}=0.42$ ) reflecting the small number of patients who responded to pembrolizumab. Nonetheless, responses were durable with $68 \%$ ongoing at 12 months compared with only $35 \%$ of chemotherapy responses ongoing at 12 months. Median OS was 10.3 months with pembrolizumab compared to 7.4 months on chemotherapy (HR 0.73, 95\% CI $0.59-0.91$, $\mathrm{p}=0.002$ ). Grade $3-5$ toxicity was seen in $15 \%$ of patients on pembrolizumab compared to $49 \%$ on chemotherapy. Benefit was seen irrespective of the choice of chemotherapy given and irrespective of PD-L1 expression by CPS\%. ${ }^{38}$

Atezolizumab was compared with investigators' choice of paclitaxel, docetaxel or vinflunine in the phase III IMvigor 211 study, sharing a similar overall design with the Keynote 045 study. One important study design difference was the use of a hierarchical fixed-sequence procedure for endpoint analysis, according to PD-L1 expression. The primary endpoint of OS was tested in successive subgroups defined by PD-L1 expression: IC2/3 ( $\geq 5 \%$ expression on tumour-infiltrating immune cells) followed by IC $1 / 2 / 3$ ( $\geq 1 \%$ expression on tumour-infiltrating immune cells) followed by the overall ITT group. Demonstration of superior OS was required in each group before the next group could be tested. No OS benefit was seen for atezolizumab compared with chemotherapy in the first group of 234 patients with IC2/3 positive disease. In this population, median OS was 11.1 months vs 10.6 months on chemotherapy (HR 0.87, $\mathrm{p}=0.41$ ). A survival benefit favoring atezolizumab was seen in the exploratory analysis of the ITT population of 931 patients (HR 0.85, 95\% CI $0.73-0.99$ ). In this study, PD-L1 positivity seemed to predict benefit from chemotherapy as well as immunotherapy. The theme of durable immunotherapy responses was seen in this study with median duration of response of 21.7 months in the ITT population compared with 7.4 months for chemotherapy in the ITT population. ${ }^{39}$

Several single arm phase I and II studies have evaluated outcomes of checkpoint inhibitors in the second line setting as outline in Table $3 .{ }^{40-47}$ Response rates have ranged 
between 15 - 31\% with complete responses ranging between $2 \%$ and $11 \%$. Median progression free survival has ranged between 1.6 months and 2.8 months, reflecting the relatively overall low proportion who benefit. Nonetheless, those who do respond seem to obtain durable benefit. Grade $3-5$ toxicity has been observed in $8-22 \%$ of patients.

\section{The role of PD-L1 testing in selecting patients for immunotherapy}

- In the second line setting PD-L1 testing by IHC should not be used to select patients for immunotherapy

In the second line setting, findings from both the Keynote 045 and IMvigor 211 randomized phase III studies suggest that benefit of checkpoint inhibitors is not limited to those with PD-L1-positive tumours by IHC. In Keynote 045, the ORR to pembrolizumab was similar in the CPS $\geq 10 \%$ population (22\%) compared to the overall population (21\%). Superior OS of pembrolizumab compared with chemotherapy was demonstrated in both the CPS $\geq 10 \%$ population and the overall population. In the IMvigor 211 trial, ORR was higher in the IC2/3 population (23\%) compared to the ITT population (13\%). Paradoxically, superior OS of Atezolizumab compared with chemotherapy was seen in the exploratory analysis of the ITT population, but not in the primary analysis of the IC2/3 subgroup.

Di Nunno et al combined the results of both randomized control trial s (RCT)s in a meta-analysis and found that immunotherapy improved OS in the ITT population but not in the high PD-L1 population. Heterogeneity between trials was greater in the PD-L1 high population compared with the ITT population demonstrating the need to further elucidate the role of PD-L1 as a predictive biomarker ${ }^{48}$

As illustrated in Tables 1 and 2, numerous phase I and II studies of checkpoint inhibitors have evaluated ORR according to PD-L1 status in both first and second line settings. In some, but not all studies, PD-L1 positivity has been associated with a higher ORR. These findings are exploratory in nature. To date no single biomarker has been able to predict response to I-O therapies in urothelial carcinoma. ${ }^{49}$

In the first line setting, the role of PD-L1 as a predictive biomarker will become clearer once results from ongoing RCTs become available. Recent safety reports have been issued from the Data Monitoring Committees of two current phase III trials comparing PD-1 / PD-L1 inhibitors (pembrolizumab in Keynote - 361, and atezolizumab in IMvigor 130) to either cisplatin or carboplatin combined with gemcitabine in first line urothelial carcinoma. Reduced efficacy of checkpoint blockade compared to chemotherapy was observed in patients with low PD-L1 expression. ${ }^{50}$

\section{Current approvals and the status of the evidence of immunotherapy in advanced urothelial carcinoma}

In the first line setting, neither pembrolizumab nor atezolizumab has been approved by Health Canada (Health Canada, 2018). ${ }^{51}$ Both agents received accelerated approval by both the FDA 
(Food and Drug Administration) and the EMA (European Medicines Agency) for cisplatinineligible patients, ${ }^{50,52}$ and are endorsed by NCCN in this population. ${ }^{53}$ Recently the indication has been narrowed to those patients whose tumours are PD-L1 positive, or who are not eligible for any platinum chemotherapy regardless of PD-L1 expression. An application for first line pembrolizumab along similar lines to FDA and EMA approvals has been made to the PanCanadian Oncology Drug Review (pCODR). ${ }^{54}$

In the second line setting, pembrolizumab, atezolizumab, durvalumab and avelumab have been approved by Health Canada for use in patients progressing during or following platinumbased chemotherapy or those who relapse within 12 months of receiving neoadjuvant or adjuvant platinum based chemotherapy for earlier stage disease. ${ }^{50}$ An expert review committee on behalf of pCODR recommended approval of pembrolizumab in this setting conditional upon 'cost effectiveness being improved to an acceptable level' ${ }^{4} \quad$ All five PD-1 / PD-L1 inhibitors discussed have FDA approval in this setting and pembrolizumab, atezolizumab and nivolumab have EMA approval. ${ }^{50,52}$

There was robust debate about the level of evidence required to recommend these agents particularly in first line setting for patients not suitable for platinum based chemotherapy. Nonetheless, the majority of GUMOC members preferred to maintain the standard of endorsing new treatments on the basis of both statistically significant and clinically meaningful benefit demonstrated in randomized phase III trials. Currently this level of evidence has not been achieved for pembrolizumab or atezolizumab in the first line setting. By the same standard, pembrolizumab is the only checkpoint inhibitor to have demonstrated this level of evidence in the second line setting. GUMOC recognize that the current consensus statements may need updating depending on the results of several ongoing phase III trials of checkpoint inhibitors (table 5).

Management of cT4b and / or cN1-3 urothelial carcinoma of the bladder:

- Patients with clinically staged T4b or N1-3 urothelial carcinoma of the bladder should be discussed in a multidisciplinary forum including an experienced Urologist / Uro-Oncologist and Radiation Oncologist.

- Patients with cT4b and / or cN1-3 urothelial carcinoma of the bladder can be cured using multi-modality treatment.

- In suitable patients, the preferred approach is to commence systemic chemotherapy with 4 - 6 cycles of platinum based chemotherapy as per 'first line systemic therapy'.

- Depending on response to initial chemotherapy, consolidation with either RC + pelvic lymph node dissection (PLND) or radical radiotherapy $(+/$ - concurrent chemotherapy) can be administered. 


\section{Unresectable locally advanced and metastatic urothelial carcinoma}

In UC of the bladder, clinical T4b disease is defined as a tumour which invades the pelvic wall, abdominal wall or adjacent bowel / rectum and is unresectable unless significant downstaging can be achieved. Clinical N1-2 disease consists of lymph node involvement in the true pelvis, whereas N3 consists of common iliac lymph node involvement. Not all patients with regional node involvement will have distant metastases, particularly with cN1-2 stage disease. The definition of nodal metastases changed in 2010 with the $7^{\text {th }}$ edition of the AJCC. ${ }^{55}$ In prior editions, common iliac lymph node involvement was considered to be metastatic and N1-3 defined nodes of varying number and size in the true pelvis.

Evidence defining the optimum treatment of cT4b and cN1-3 disease is limited to retrospective series. These patients have been routinely excluded from neoadjuvant chemotherapy trials, and in the Advanced Bladder Cancer meta-analysis of neo-adjuvant chemotherapy, represented only $1 \%$ and $4 \%$ of cases, respectively. ${ }^{56}$ Likewise, these patients have generally been excluded from chemoradiotherapy studies. ${ }^{57}$ Consequently the optimum management of this subgroup of patients is not well defined.

A commonly used treatment paradigm in published series has consisted of induction chemotherapy (IC) followed by RC or HDRT in select patients. ${ }^{58-67}$ Several studies utilizing this approach are outlined in table 3. Only the study by Nieuwenhuijzen required histological confirmation of involved lymph nodes. ${ }^{60}$ Radical cystectomy / PLND was the most commonly used consolidation treatment with HDRT only utilized in a subset of patients in two studies. The study by Urakami included 29 patients with upper tract UC out of 60 patients. ${ }^{63}$ All other studies were restricted to UC of the bladder. Most studies did not define specific selection criteria for RC or HDRT, however the study by Nieuwenhuijzen required a response to induction chemotherapy in order to proceed to RC and the study by Urakami selected patients with responsive or stable disease. The study by Als had a unique design whereby patients who obtained a CR based on both CT imaging and cystoscopy and biopsy underwent close surveillance whereas patients who had a partial response received either RC or HDRT. ${ }^{62}$ Although the study by Herr did not define criteria for RC, 80 patients out of an initial 207 pts receiving chemotherapy proceeded to $\mathrm{RC}$, implying that patients were carefully selected for surgery. ${ }^{65}$ The study by Black evaluated cT4b patients who had achieved sufficient downstaging from IC to become resectable. ${ }^{61}$ Most studies administered 4 cycles of chemotherapy. Results from the above studies demonstrate the potential for cure with reported 5 year cancer specific survival (CSS) / OS ranging from 23 - 60\%. On this basis, GUMOC considered it reasonable to endorse the above treatment strategy for this group of patients. A further argument for a curative treatment approach is the potential for inaccurate clinical staging of lymph nodes. In studies of patients with cN1-3 who have proceeded directly to surgery a proportion have had pN0 disease implying false positive clinical staging. ${ }^{68}$ A benefit of commencing treatment with IC is to spare patients who have significant disease progression the morbidity of surgery and / or HDRT. 
Selection criteria which should be applied to the decision of consolidative treatment following IC are not clear from the above studies. In general, outcomes are better in patients with a response to IC; however both Ho and Meijer report a 20\% 5 year OS in patients with stable disease on IC ${ }^{66,67}$, indicating these patients can still obtain benefit. In general, the choice of consolidative treatment is best made on an individual basis with multidisciplinary input. Nonetheless, there are two situations which would sway our decision towards HDRT as opposed to surgery. The first is a patient with persistent N3 disease after IC, where the risk of relapse is high and HDRT represents a less invasive treatment option. The second is for a patient with cT4b disease who fails to obtain down staging with IC, where surgery is usually not feasible.

The role of aggressive surgical / radiotherapeutic management in oligometastastic disease.

- Routine practice of metastasectomy / localized treatment to metastatic disease in patients with oligometastatic or limited metastatic disease is not recommended. However, such treatment may be appropriate in selected cases. (See discussion).

- In metastatic UC of the bladder, the routine practice of RC or HDRT (+/chemotherapy) to the primary is not recommended. However, such treatment may be appropriate in selected cases (See discussion).

- The decision to treat oligometastatic disease with local therapies should be made in a multidisciplinary context with involvement of an experienced medical oncologist, uro-oncologist and radiation oncologist where appropriate.

The targeting of oligometastatic disease with surgical resection and / or ablative radiotherapy has only been tested in small series of highly selected patients with no randomized studies to guide practice. While outcomes have been impressive with reports of 5 year OS of up to $65 \%{ }^{69,70}$, uncertainty exists as to whether favourable outcomes were the result of selection bias or from a therapeutic benefit of the localized therapy studied. Further compounding the problem of applying these studies to routine practice is the fact that the majority of studies were retrospective without clearly defined criteria for which patients should receive the localized treatment under consideration. The same limitation applies to the evidence for aggressive localized treatment of the pelvic primary with RC or HDRT (+/- concurrent chemotherapy) in a patient with metastatic disease. In short, the literature provides no level 1 evidence to be either prescriptive or proscriptive with regard to the above treatments. The existing literature is prone to methodological bias. ${ }^{71}$

Individualization of local treatment following systemic treatment is the most judicious approach. The aggressiveness of the local treatment will vary according to the initial local stage and the subsequent local and systemic response to the chemotherapy. In any given patient, TURBT (trans-urethral resection of bladder tumor), pelvic radiotherapy with or without concurrent chemotherapy, metastasectomy or ablative radiotherapy may be appropriate. Recognizing this dearth of compelling data emphasizes that individually tailored treatment by a multidisciplinary team will serve the patient best. 
Patients for whom multidisciplinary input may be useful include those with oligometastatic disease, advanced pelvic disease (without hematogenous metastases) with a response to systemic therapy, and those with hematogenous metastases with a complete response at least pertaining to their metastatic disease.

\section{Future directions}

The management of locally advanced and metastatic urothelial carcinoma is a rapidly changing field. Ongoing randomized phase III studies of immunotherapy for advanced urothelial carcinoma are summarized in Table $5 .^{72}$ Additionally, work is being done on identifying predictive biomarkers which will help in patient selection. Upper tract urothelial carcinoma is associated with microsatellite instability in $3-6 \%$ of cases and this may be a useful biomarker to evaluate with respect to the efficacy of immunotherapy. ${ }^{73,74}$ The association with Lynch syndrome should be noted and the role of universal screening versus risk adapted screening could be evaluated in subsequent updates. ${ }^{72}$ Immunotherapy studies are also taking place in the earlier stages of disease which has the potential to alter the profile of the patient presenting with subsequent locally advanced or metastatic disease. Immunotherapy may also change the profile of patients being considered for aggressive local therapies in the context of metastatic disease. Due to the rapid evolution of therapy in this disease state, these consensus statements will need regular updating.

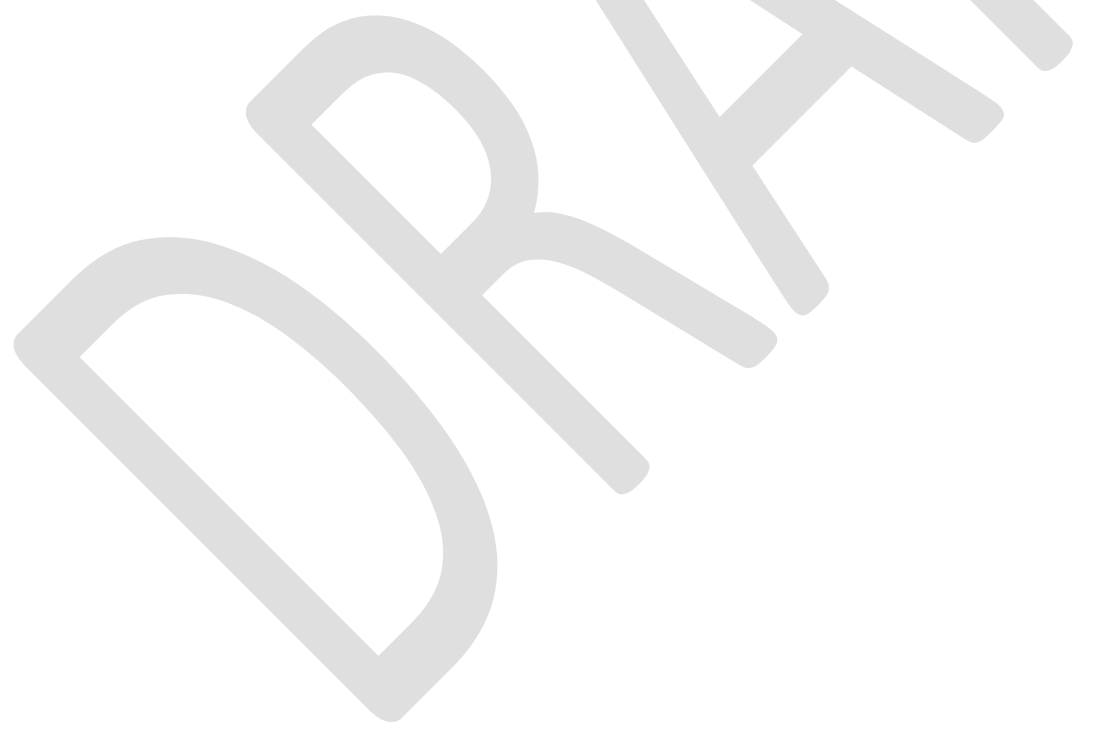




\section{References}

1. Canadian Cancer Statistics Advisory Committee: Canadian Cancer Society. Canadian Cancer Statistics 2018: Toronto, ON. www.cancer.ca/en. Accessed February 20, 2019.

2. Galsky MD, Hahn NM, Rosenberg J, et al. A consensus definition of patients with metastatic urothelial carcinoma who are unfit for cisplatin-based chemotherapy. Lancet Oncol 2011;12:211-14.

3. Gonzalez CM, Jordan E, Zabor EC, et al. Split-dose cisplatin as an alternative to every-3week dosing when using cisplatin/gemcitabine to treat advanced urothelial cancer. $J$ Clin Oncol 2015;33:7S:373.

4. Morales-Barrera R, Bellmunt J, Suárez C, et al. Cisplatin and gemcitabine administered every two weeks in patients with locally advanced or metastatic urothelial carcinoma and impaired renal function. Eur J Cancer 2012;48:1816-21.

5. von der Maase H, Sengelov L, Roberts JT, et al. Long-term survival results of a randomized trial comparing gemcitabine plus cisplatin, with methotrexate, vinblastine, doxorubicin, plus cisplatin in patients with bladder cancer. J Clin Oncol 2005;23:4602-08.

6. von der Maase H, Hansen SW, Roberts JT, et al. Gemcitabine and cisplatin versus methotrexate, vinblastine, doxorubicin, and cisplatin in advanced or metastatic bladder cancer: Results of a large, randomized, multinational, multicenter, phase III study. J Clin Oncol 2000;17:3068-77.

7. Bajorin DF, Dodd PM, Mazumdar M, et al. Long-term survival in metastatic transitionalcell carcinoma and Prognostic Predicting Outcome of Therapy. J Clin Oncol 1999;17:3173-81.

8. Sternberg CN, De Mulder P, Schornagel JH, et al. Seven year update of an EORTC phase III trial of high-dose intensity M-VAC chemotherapy and G-CSF versus classic M-VAC in advanced urothelial tract tumours. Eur J Cancer 2006;42:50-54.

9. Bamias A, Dafni U, Karadimou A, et al. Prospective, open-label, randomized, phase III study of two dose-dense regimens MVAC versus gemcitabine/ cisplatin in patients with inoperable, metastatic or relapsed urothelial cancer: A Hellenic Cooperative Oncology Group study (HE 16/03). Ann Oncol 2013;24:1011-17.

10. Plimack ER, Hoffman-Censits JH, Kutikov A, et al. Neoadjuvant dose-dense gemcitabine and cisplatin (DDGC) in patients (pts) with muscle-invasive bladder cancer (MIBC): Final results of a multicenter phase II study. J Clin Oncol 2014;32:15S:4513.

11. Bellmunt J, von der Maase H, Mead GM, et al. Randomized phase III study comparing paclitaxel/cisplatin/gemcitabine and gemcitabine/cisplatin in patients with locally advanced or metastatic urothelial cancer without prior systemic therapy: EORTC intergroup study 30987. J Clin Oncol 2012;30:1107-13.

12. Galsky MD, Chen GJ, Oh WK, et al. Comparative effectiveness of cisplatin-based and carboplatin-based chemotherapy for treatment of advanced urothelial carcinoma. Ann Oncol 2012;23:406-10.

13. De Santis M, Bellmunt J, Mead G, et al. Randomized phase II/III trial assessing gemcitabine/carboplatin and methotrexate/carboplatin/vinblastine in patients with advanced urothelial cancer who are unfit for cisplatin-based chemotherapy: EORTC study 30986. J Clin Oncol 2012;30:191-99. 


\section{Unresectable locally advanced and metastatic urothelial carcinoma}

14. Hussain M, Vaishampayan U, Du W. Combination paclitaxel, carboplatin and gemcitabine is an active treatment for advanced urothelial cancer. J Clin Oncol 2001;19:2527-33.

15. Galsky MD, Iasonos A, Mironov S. Phase II trial of dose-dense doxorubicin plus gemcitabine followed by paclitaxel plus carboplatin in patients with advanced urothelial carcinoma and impaired renal function. Cancer 2007;109:549-55.

16. Meluch AA, Greco FA, Burris HA, et al. Paclitaxel and gemcitabine chemotherapy for advanced transitional-cell carcinoma of the urothelial tract: A phase II trial of the Minnie Pearl Cancer Research Network. J Clin Oncol 2001;19:3018-24.

17. Calabrò F, Lorusso V, Rosati G, et al. Gemcitabine and paclitaxel every 2 weeks in patients with previously untreated urothelial carcinoma. Cancer 2009;115:2652-59.

18. Kaufman DS, Carducci MA, Kuzel TM, et al. A multi-institutional phase II trial of gemcitabine plus paclitaxel in patients with locally advanced or metastatic urothelial cancer. Urol Oncol 2004;22:393-97.

19. Li J, Juliar B, Yiannoutsos C, et al. Weekly paclitaxel and gemcitabine in advanced transitional-cell carcinoma of the urothelium: A phase II Hoosier Oncology Group study. J Clin Oncol 2005;23:1185-91.

20. Ardavanis A, Tryfonopoulos D, Alexopoulos A, et al. Gemcitabine and docetaxel as firstline treatment for advanced urothelial carcinoma: A phase II study. Br J Cancer 2005;92:645-50.

21. Gitlitz BJ, Baker C, Chapman Y, et al. A phase II study of gemcitabine and docetaxel therapy in patients with advanced urothelial carcinoma. Cancer 2003;98:1863-69.

22. de Wit R, Kruit WHJ, Stoter G, et al. Docetaxel (Taxotere): An active agent in metastatic urothelial cancer; Results of a phase II study in non-chemotherapy-pretreated patients. $\mathrm{Br}$ J Cancer 1998;78:1342-45.

23. Roth BJ, Dreicer R, Einhorn LH, et al. Significant activity of paclitaxel in advanced transitional-cell carcinoma of the urothelium: A phase II trial of the Eastern Cooperative Oncology Group. J Clin Oncol 1994;12:2264-70.

24. Moore MJ, Tannock IF, Ernst DS, et al. Gemcitabine: A promising new agent in the treatment of advanced urothelial cancer. J Clin Oncol 1997;15:3441-45.

25. Stadler WM, Kuzel T, Roth B, et al. Phase II study of single-agent gemcitabine in previously untreated patients with metastatic urothelial cancer. J Clin Oncol. 1997;15:3394-98.

26. Balar AV, Castellano D, O’Donnell PH, et al. First-line pembrolizumab in cisplatinineligible patients with locally advanced and unresectable or metastatic urothelial cancer (KEYNOTE-052): a multicentre, single-arm, phase 2 study. Lancet Oncol 2017;18:148392.

27. Vuky J, Balar A V, Castellano DE. et al. Updated efficacy and safety of KEYNOTE-052: A single arm phase 2 study investigating first-line pembrolizumab (pembro) in cisplatinineligible advanced urothelial cancer (UC). J Clin Oncol. 2018;36;15S:4524.

28. Balar AV, Galsky MD, Rosenberg JE, et al. Atezolizumab as first-line treatment in cisplatin-ineligible patients with locally advanced and metastatic urothelial carcinoma: a single-arm, multicentre, phase 2 trial. Lancet 2017;389:67-76.

29. Oing C, Rink M, Oechsle K, Seidel C, et al. Second line chemotherapy for advanced and 


\section{Unresectable locally advanced and metastatic urothelial carcinoma}

metastatic urothelial carcinoma: Vinflunine and beyond - a comprehensive review of the current literature. J Urol 2016;195:254-63.

30. Han KS, Joung JY, Kim TS, et al. Methotrexate, vinblastine, doxorubicin and cisplatin combination regimen as salvage chemotherapy for patients with advanced or metastatic transitional cell carcinoma after failure of gemcitabine and cisplatin chemotherapy. $\mathrm{Br} \mathrm{J}$ Cancer 2008;98:86-90.

31. Kattan J, Culine S, Theodore C, et al. Letters to the editor: Second-line M-VAC therapy in patients previously treated with the M-VAC regimen for metastatic urothelial cancer. Ann Oncol 1993;4:793-94.

32. Bellmunt J, Théodore C, Demkov T, et al. Phase III trial of vinflunine plus best supportive care compared with best supportive care alone after a platinum-containing regimen in patients with advanced transitional cell carcinoma of the urothelial tract. J Clin Oncol 2009;27:4454-61.

33. Raggi D, Miceli R, Sonpavde G, et al. Second-line single-agent versus doublet chemotherapy as salvage therapy for metastatic urothelial cancer: A systematic review and meta-analysis. Ann Oncol 2016;27:49-61.

34. Vaughn DJ, Broome CM, Hussain M, et al. Phase II trial of weekly paclitaxel in patients with previously treated advanced urothelial cancer. J Clin Oncol 2002;20:937-40.

35. Papamichael D, Gallagher CJ, Oliver RTD, et al. Phase II study of paclitaxel in pretreated patients with locally advanced/metastatic cancer of the bladder and ureter. $\mathrm{Br} \mathrm{J}$ Cancer 1997;75:606-07.

36. McCaffrey JA, Hilton S, Mazumdar M, et al. Phase II trial of docetaxel in patients with advanced or metastatic transitional-cell carcinoma. J Clin Oncol 1997;15:1853-57.

37. Ko Y, Canil CM, Mukherjee SD, et al. Nanoparticle albumin-bound paclitaxel for secondline treatment of metastatic urothelial carcinoma : a single group , multicentre , phase 2 study. Lancet Oncol 2013;14:769-76.

38. Bellmunt J, de Wit R, Vaughn DJ, et al. Pembrolizumab as second-line therapy for advanced urothelial carcinoma. $N$ Engl J Med 2017;376:1015-26.

39. Powles T, Durán I, van der Heijden MS, et al. Atezolizumab versus chemotherapy in patients with platinum-treated locally advanced or metastatic urothelial carcinoma (IMvigor211): A multicentre, open-label, phase 3 randomised controlled trial. Lancet 2017;391:748-57.

40. Sharma P, Callahan MK, Bono P, et al. Nivolumab monotherapy in recurrent metastatic urothelial carcinoma (CheckMate 032): a multicentre, open-label, two-stage, multi-arm, phase 1/2 trial. Lancet Oncol 2016;17:1590-98.

41. Sharma P, Retz M, Siefker-Radtke A, et al. Nivolumab in metastatic urothelial carcinoma after platinum therapy (CheckMate 275): a multicentre, single-arm, phase 2 trial. Lancet Oncol 2017;18:312-22.

42. Massard C, Gordon MS, Sharma S, et al. Safety and efficacy of durvalumab (MEDI4736), an anti-programmed cell death ligand-1 immune checkpoint inhibitor, in patients with advanced urothelial bladder cancer. J Clin Oncol 2016;34:3119-125.

43. Powles T, O'Donnell PH, Massard C, et al. Efficacy and safety of durvalumab in locally advanced or metastatic urothelial carcinoma: Updated results From a phase 1/2 open-label Study. JAMA Oncol 2017;3:e172411. 


\section{Unresectable locally advanced and metastatic urothelial carcinoma}

44. Rosenberg JE, Hoffman-Censits J, Powles T, et al. Atezolizumab in patients with locally advanced and metastatic urothelial carcinoma who have progressed following treatment with platinum-based chemotherapy: A single-arm, multicentre, phase 2 trial. Lancet 2016;387:1909-20.

45. Petrylak DP, Powles T, Bellmunt J, et al. Atezolizumab (MPDL3280A) monotherapy for patients with metastatic urothelial cancer: Long-term outcomes from a phase 1 study. JAMA Oncol 2018;4:537-44.

46. Patel MR, Ellerton J, Infante JR, et al. Avelumab in metastatic urothelial carcinoma after platinum failure (JAVELIN Solid Tumor): pooled results from two expansion cohorts of an open-label, phase 1 trial. Lancet Oncol 2018;19:51-64.

47. Plimack ER, Bellmunt J, Gupta S, et al. Safety and activity of pembrolizumab in patients with locally advanced or metastatic urothelial cancer (KEYNOTE-012): a nonrandomised, open-label, phase 1b study. Lancet Oncol 2017;18:212-20.

48. Di Nunno V, De Luca E, Buttigliero C, et al. Immune-checkpoint inhibitors in previously treated patients with advanced or metastatic urothelial carcinoma : A systematic review and meta-analysis. Crit Rev Oncol / Hematol 2018;129:124-32.

49. Lavoie J-M, Black PC, Eigl BJ. Predictive biomarkers for checkpoint blockade in urothelial cancer: A systemic review. J Urol 2019;136:Epub ahead of print Feb 4.

50. FDA.gov: U.S. Food and Drug Administration. https://www.fda.gov/. Accessed April 10, 2019.

51. Canada.ca. Health Canada. https://www.canada.ca/en/health-canada.html. Accessed February 20, 2019.

52. EMA.Europa.ed. European Medicines Agency. https://www.ema.europa.eu/. Accessed February 20, 2019.

53. NCCN.org. NCCN: National Comprehensive Cancer Network Practice Network. Practice Guidelines in Oncology Bladder version 1.2019 - Dec 20, 2018. https://www.nccn.org. Accessed February 21, 2019.

54. CADTH.ca: pan Canadian Oncology Drug Review. https://cadth.ca/pcodr. Accessed February 20, 2019.

55. Edge S, Byrd D, Compton C, (editors). AJCC cancer staging manual. https://www.springer.com/gp/book/9780387884424. Published 2010.

56. Advanced Bladder Cancer (ABC) Meta-analysis Collaboration: Neoadjuvant chemotherapy in invasive bladder cancer : a systematic review and meta-analysis. Lancet 2003;361:1927-34.

57. James N, Hussain S, Hall E,et al. Radiotherapy with or without chemotherapy in muscleinvasive bladder cancer. N Engl J Med 2012;366:1477-88.

58. Zargar-Shoshtari K, Zargar H, Lotan Y, et al. A multi-institutional analysis of outcomes of patients with clinically node positive urothelial bladder cancer treated with induction chemotherapy and radical cystectomy. J Urol 2016;195:53-59.

59. Abufaraj M, Dalbagni G, Daneshand S, et al. The role of surgery in metastatic bladder cancer: A systematic review. Eur Urol 2018;73:543-57.

60. Nieuwenhuijzen JA, Bex A, Meinhardt W, et al. Neoadjuvant methotrexate, vinblastine, doxorubicin and cisplatin for histologically proven lymph node positive bladder cancer. $J$ Urol 2005;174:80-84. 


\section{Unresectable locally advanced and metastatic urothelial carcinoma}

61. Black PC, Dinney CPN, Brown GA, et al. The role of radical cystectomy in patients with clinical T4b bladder cancer. Urol Oncol 2011;29:157-61.

62. Als AB, Sengelov L, von der Maase H. Long-term survival after gemcitabine and cisplatin in patients with locally advanced transitional cell carcinoma of the bladder: Focus on supplementary treatment strategies. Eur Urol 2007;52:478-87.

63. Urakami S, Yuasa T, Yamamoto S, Sakura M. Clinical response to induction chemotherapy predicts improved survival outcome in urothelial carcinoma with clinical lymph nodal metastasis treated by consolidative surgery. Int J Clin Oncol. 2015;20:11711178.

64. Ghadjar P, Burkhard FC, Gautschi O, et al. Induction chemotherapy for unresectable urothelial carcinoma of the bladder. BJU Int 2010;107:894-97.

65. Herr HW, Donat SM, Bajorin DF. Post-chemotherapy surgery in patients with unresectable or regionally metastatic bladder cancer. J Urol 2001;165:811-14.

66. Ho PL, Willis DL, Patil J, et al. Outcome of patients with clinically node-positive bladder cancer undergoing consolidative surgery after preoperative chemotherapy: The M.D.

Anderson Cancer Center Experience. Urol Oncol 2016;34:59.e1-8.

67. Meijer RP, Mertens LS, Rhijn BW Van, et al. Induction chemotherapy followed by surgery in node positive bladder cancer. Urology 2014;83:134-39.

68. Hermans TJN, Fransen van de Putte EE, Horenblas S, et al. Pathological downstaging and survival after induction chemotherapy and radical cystectomy for clinically node-positive bladder cancer-Results of a nationwide population-based study. Eur J Cancer 2016;69:1-8.

69. Han WS, Kim K, Park JS. Result of surgical resection for pulmonary metastasis from urothelial carcinoma. Korean J Thorac Cardiovasc Surg 2012;45:242-45.

70. Cowles RS, Johnson DE, McMurtrey MJ. Long-term results following thoracotomy for metastatic bladder cancer. Urology 1982;20:390-92.

71. Booth CM, Karim S, Peng Y, et al. Radical treatment of the primary tumor in metastatic bladder Cancer : Potentially dangerous findings from observational data. J Clin Oncol 2018;36:533-35.

72. ClinicalTrials.gov. NIH U.S. National Library of Medicine. https://clinicaltrials.gov. Published 2019. Accessed February 21, 2019.

73. Metcalfe MJ, Petros FG, Rao P, et al. Universal point of care testing for Lynch Syndrome in patients with upper tract urothelial carcinoma. J Urol 2018;199:60-65.

74. Ju JY, Mills AM, Mahadevan MS, et al. Universal Lynch Syndrome screening should be performed in all upper tract urothelial carcinomas. 2018;42:1549-55. 
Figures and Tables

\begin{tabular}{|c|c|}
\hline Treatment regimen & Schedule \\
\hline $\begin{array}{l}\text { Gemcitabine, } \\
\text { cisplatin (GC) }\end{array}$ & $\begin{array}{l}\text { Cisplatin } 70 \mathrm{mg} / \mathrm{m}^{2} \text { day } 1 \text { (in split dose } 35 \mathrm{mg} / \mathrm{m}^{2} \text { day } 1,8 \text { ) } \\
\text { Gemcitabine } 1200 \mathrm{mg} / \mathrm{m}^{2} \text { day } 1,8 \text {, } \\
\text { Cycle length } 21 \text { days }\end{array}$ \\
\hline $\begin{array}{l}\text { Dose dense- } \\
\text { Methotrexate, } \\
\text { vinblastine, } \\
\text { doxorubicin, } \\
\text { cisplatin (DD- } \\
\text { MVAC) }\end{array}$ & $\begin{array}{l}\text { Methotrexate } 30 \mathrm{mg} / \mathrm{m}^{2} \text { day } 1 \\
\text { Vinblastine } 3 \mathrm{mg} / \mathrm{m}^{2} \text { day } 2 \\
\text { Doxorubicin } 30 \mathrm{mg} / \mathrm{m}^{2} \text { day } 2 \\
\text { Cisplatin } 70 \mathrm{mg} / \mathrm{m}^{2} \text { day } 2 \\
\text { G-CSF: day } 3-7 \\
\text { Cycle length } 14 \text { days }\end{array}$ \\
\hline $\begin{array}{l}\text { Gemcitabine, } \\
\text { Carboplatin (GCa) }\end{array}$ & $\begin{array}{l}\text { Carboplatin AUC } 5 \text { day } 1 \\
\text { Gemcitabine } 1000 \mathrm{mg} / \mathrm{m}^{2} \text { day } 1,8 \\
\text { Cycle length } 21 \text { days }\end{array}$ \\
\hline Gemcitabine (G) & $\begin{array}{l}\text { Gemcitabine } 1200 \mathrm{mg} / \mathrm{m}^{2} \text { day } 1,8,15 \\
\text { Cycle length } 28 \text { days }\end{array}$ \\
\hline Paclitaxel (P) & $\begin{array}{l}\text { Paclitaxel } 175 \mathrm{mg} / \mathrm{m}^{2} \\
\text { Cycle lenth } 21 \text { days }\end{array}$ \\
\hline Docetaxel (D) & $\begin{array}{l}\text { Docetaxel } 75 \mathrm{mg} / \mathrm{m}^{2} \\
\text { Cycle lenth } 21 \text { days }\end{array}$ \\
\hline Pembrolizumab & $\begin{array}{l}\text { Pembrolizumab: } 200 \mathrm{mg} \text { IV } \\
\text { Cycle length } 21 \text { days }\end{array}$ \\
\hline
\end{tabular}




\section{Table 2. Summary of first-line immunotherapy studies in cisplatin ineligible patients with advanced urothelial carcinoma}

\begin{tabular}{|c|c|c|}
\hline & $\begin{array}{c}\text { Pembrolizumab: Keynote } \\
052 \\
\end{array}$ & $\begin{array}{c}\text { Atezolizumab: Imvigor } 210 \\
\text { cohort } 1\end{array}$ \\
\hline Study type & $\begin{array}{l}\text { Multicentre, single-arm phase } \\
2 \\
\text { Cisplatin-ineligible, first-line }\end{array}$ & $\begin{array}{l}\text { Multicentre, single-arm, } \\
\text { phase } 2 \\
\text { Cisplatin-ineligible, first-line }\end{array}$ \\
\hline Treatment regimen & $\begin{array}{c}\text { Pembrolizumab } 200 \text { mg IV } 3 \\
\text { weekly }\end{array}$ & $\begin{array}{l}\text { Atezolizumab } 1200 \mathrm{mg} \text { IV } 3 \\
\text { weekly }\end{array}$ \\
\hline Number of patients & 370 & 119 \\
\hline Median followup (months) & 11.5 & 17.2 \\
\hline ECOG 2\% & 42 & 27 \\
\hline Visceral metastases\% & 85 & 66 \\
\hline ORR\% & 29 & 23 \\
\hline $\mathrm{Cr} \%$ & 8 & 9 \\
\hline Response duration & $68 \%$ ongoing at 12 months & $\begin{array}{c}\text { 70\% ongoing at time of } \\
\text { assessment }\end{array}$ \\
\hline Median OS (months) & 11.5 & 15.9 \\
\hline Effect of PD-L1 positivity & $\begin{array}{l}\text { Combined positive score } \\
\text { (CPS): } \\
\geq 10 \% \text { : ORR } 47.3 \% \\
\text { 1-10\%: ORR: } 20 \% \\
\text { <1\%: ORR } 5 \%\end{array}$ & $\begin{array}{l}\text { IC } 2 / 3: \text { ORR } 28 \% \\
\text { IC 1: ORR } 21 \% \\
\text { IC 0: ORR } 21 \%\end{array}$ \\
\hline Grade $3 / 4$ toxicity & $16 \%$ & $16 \%$ \\
\hline Reference & $\begin{array}{l}\text { Balar } 2017^{26} \\
\text { Vuky }^{27}\end{array}$ & Balar $^{28}$ \\
\hline
\end{tabular}

Cr: creatinine; ECOG: Eastern Cooperative Oncology Group; ORR: overall response rate; OS: overall survival. 


\begin{tabular}{|c|c|c|c|c|c|c|c|}
\hline $\begin{array}{l}\text { Checkpoint } \\
\text { inhibitor }\end{array}$ & $\begin{array}{c}\text { Nivolumab } \\
\text { Checkmate } 032\end{array}$ & $\begin{array}{c}\text { Nivolumab } \\
\text { Checkmate } 275\end{array}$ & $\begin{array}{c}\text { Durvalumab } \\
\text { MEDI4736 }\end{array}$ & $\begin{array}{c}\text { Atezolizumab } \\
\text { Imvigor } 210 \\
\text { cohort II }\end{array}$ & Atezolizumab & $\begin{array}{c}\text { Avelumab } \\
\text { Javelin Solid } \\
\text { Tumour }\end{array}$ & $\begin{array}{c}\text { Pembrolizumab } \\
\text { Keynote } 012\end{array}$ \\
\hline Study type & Phase $1 / 2$ & Phase 2 & $\mathrm{Ph} 1 / 2$ & Phase 2 & Phase 1 & Phase 1 & Phase 1b \\
\hline Patients & 86 & 270 & 191 & 315 & 95 & 161 & 33 \\
\hline $\begin{array}{l}\text { ORR\% (95\% } \\
\text { CI) }\end{array}$ & $24(15-35)$ & $20(15-24)$ & $18(13-24)$ & $15(11-19)$ & $26(18-36)$ & $17(11-24)$ & $26(11-46)$ \\
\hline $\mathrm{Cr} \%$ & 6 & 2 & 4 & 5 & 9 & 6 & 11 \\
\hline $\begin{array}{l}\text { Response } \\
\text { duration }\end{array}$ & $\begin{array}{c}\text { Median } 9.4 \\
\text { months }\end{array}$ & $\begin{array}{l}77 \% \text { ongoing at } \\
6 \text { months }\end{array}$ & $\begin{array}{c}50 \% \text { ongoing at } \\
6 \mathrm{~m}\end{array}$ & $\begin{array}{l}84 \% \text { ongoing at } \\
\text { median f/u } 11.7 \mathrm{~m}\end{array}$ & Median 22.1m & $\begin{array}{c}\text { Median NR } \\
\text { (not reached) }\end{array}$ & Median 10m \\
\hline mPFS months & 2.8 & 2 & 1.4 & 2.1 & 2.7 & 1.6 & 2 \\
\hline mOS months & 9.7 & 8.7 & 18 & 7.9 & 10.1 & 6.5 & 10 \\
\hline $\begin{array}{l}\text { Grade 3-5 } \\
\text { toxicity\% }\end{array}$ & 22 & 18 & 6.8 & 16 & $9 \%$ & 8 & 15 \\
\hline $\begin{array}{l}\text { Effect of PD-L1 } \\
\text { on ORR\% }\end{array}$ & $\begin{array}{l}\geq 1 \%: 24 \% \\
<1 \%: 26 \%\end{array}$ & $\begin{array}{l}\geq 1 \%: 24 \% \\
<1 \%: 16 \%\end{array}$ & $\begin{array}{c}\geq 25 \% \text { IC/TC: } \\
28 \% \\
<25 \% \text { IC/TC: } 5 \%\end{array}$ & $\begin{array}{c}\text { IC2/3: } 27 \% \\
\text { ITT: } 15 \%\end{array}$ & $\begin{array}{l}\text { IC 2/3: } 40 \% \\
\text { IC 0/1: } 11 \%\end{array}$ & $\begin{array}{l}\geq 5 \%: 24 \% \\
<5 \%: 14 \%\end{array}$ & $\begin{array}{c}\geq \mathrm{TC}: 1 \%: 24 \% \\
<1: 0 \% \text { (combined } \\
\text { TC/IC measured) }\end{array}$ \\
\hline Reference & Sharma $2016^{40}$ & Sharma $2017^{41}$ & $\begin{array}{c}\text { Massard } 2016^{42} \\
\text { Powles } 2018^{43}\end{array}$ & Rosenberg $2016^{44}$ & $\begin{array}{c}\text { Petrylak } \\
2018^{45}\end{array}$ & Patel $2016^{46}$ & Plimack $2017^{47}$ \\
\hline
\end{tabular}

C: confidence interval; IC: immune cells; ORR: overall response rate; OS: overall survival; PFS: progression-free survival;TC: tumour cells; 
Unresectable locally advanced and metastatic urothelial carcinoma

\begin{tabular}{|c|c|c|c|c|c|c|}
\hline & Clinical stage & Patients (n) & $\begin{array}{c}\text { Induction } \\
\text { chemotherapy }\end{array}$ & $\begin{array}{c}\text { Consolidative } \\
\text { treatment }\end{array}$ & $\begin{array}{c}\text { Selection criteria } \\
\text { for RC and/or } \\
\text { HDRT }\end{array}$ & Survival \\
\hline Zargar-Shostari ${ }^{58}$ & $\mathrm{~T} 1-4 \mathrm{a}$ N1-3 & 304 & $\begin{array}{c}\text { GC } 43 \% \\
\text { MVAC } 42 \% \\
\text { Other } 15 \%\end{array}$ & RC/PLND & Not defined & $\begin{array}{l}\text { Median OS 23m } \\
50 \% \text { died in } \\
\text { followup }\end{array}$ \\
\hline Herr $^{65}$ & $\begin{array}{c}\text { T4bNx or T3- } \\
4 \text { N2-3 }\end{array}$ & $\begin{array}{l}80 \text { (selected } \\
\text { from 207) }\end{array}$ & $\begin{array}{c}\text { MVAC 75\% } \\
\text { Other 25\% }\end{array}$ & RC +/- PLND & Not defined & $\begin{array}{c}42 \% \text { survived } 9 \\
\text { months to } 5 \text { years } \\
\text { MVAC treated pts: } \\
32 \% \text { OS at } 5 \text { years }\end{array}$ \\
\hline $\begin{array}{l}\text { Nieuwenjuijz- } \\
\mathrm{en}^{60}\end{array}$ & $\begin{array}{l}\text { Biopsy proven } \\
\text { N+ disease } \\
\text { (40\% FNA, } \\
60 \% \text { PLND) }\end{array}$ & $\begin{array}{l}40 \text { (selected } \\
\text { from 52) }\end{array}$ & $\begin{array}{l}\text { MVAC / dd- } \\
\text { MVAC }\end{array}$ & RC/PLND & $\begin{array}{l}\text { Response to } \\
\text { induction } \\
\text { chemotherapy }\end{array}$ & $\begin{array}{c}\text { 5-year CSS (cancer } \\
\text { specific survival) } \\
23 \%\end{array}$ \\
\hline $\mathrm{Ho}^{66}$ & $\begin{array}{l}\text { cN1-3: 53\% } \\
\text { cM1: } \\
\text { retroperitoneal } \\
\text { nodes } 47 \%\end{array}$ & 55 & $\begin{array}{c}\text { Cisplatin based } \\
93 \%\end{array}$ & $\begin{array}{l}\text { RC, PLND +/- } \\
\text { RPLND }\end{array}$ & Not defined & 5-year CSS: 40\% \\
\hline Black $^{61}$ & Tb4 & 23 & $\begin{array}{c}\text { Preoperative } \\
\text { chemotherapy in } \\
83 \%\end{array}$ & RC, PLND & $\begin{array}{l}\text { Not defined, but } \\
\text { generally major } \\
\text { response to IC } \\
\text { required }\end{array}$ & 5-year OS: 60\% \\
\hline
\end{tabular}


Unresectable locally advanced and metastatic urothelial carcinoma

\begin{tabular}{|c|c|c|c|c|c|c|}
\hline $\mathrm{Als}^{62}$ & cTb4 or cN2-3 & $\begin{array}{c}84 \\
\text { (25 observed } \\
\text { after clinical } \\
\text { CR, } \\
7 \text { RC } \\
9 \text { HDRT) }\end{array}$ & GC & $\begin{array}{l}\text { CR: observation } \\
\text { PR: RC/PLND or } \\
\text { HDRT }\end{array}$ & $\begin{array}{l}\text { Clinical CR: close } \\
\text { observation } \\
\text { Clinical PR: } \\
\text { investigators } \\
\text { choice of RC or } \\
\text { RT }\end{array}$ & $\begin{array}{c}\text { 5-year OS: } \\
\text { Overall } 21 \% \\
\text { CR with observation } \\
42 \% \\
\text { NED from surgery or } \\
\text { XRT: } 49 \%\end{array}$ \\
\hline Urakami $^{63}$ & $\begin{array}{c}\text { cN1-3 and } \\
\text { M1a lymph } \\
\text { nodes only } \\
(30 \%)\end{array}$ & $\begin{array}{l}51 \text { (selected } \\
\text { from 60: } 29 \\
\text { upper tract, } 31 \\
\text { bladder) }\end{array}$ & $\begin{array}{c}\text { Platinum based } \\
\text { (GC based in 57\%). }\end{array}$ & $\begin{array}{c}\text { RC/PLND } \\
\text { Resection of } \\
\text { upper tract } \\
\text { tumours / } \\
\text { extended LND }\end{array}$ & $\begin{array}{l}\text { Stable disease or } \\
\text { response }\end{array}$ & $\begin{array}{l}\text { 5-year OS (including } \\
\text { non-operated } \\
\text { candidates) } 42 \%\end{array}$ \\
\hline Ghadjar $^{64}$ & $\begin{array}{l}\mathrm{T} 4, \mathrm{~N} 1-3, \\
\text { M1 regional } \\
\text { nodes }\end{array}$ & 30 & GC/GCa & RC/PLND & Not defined & 5-year OS 46\% \\
\hline Meijer $^{67}$ & $\begin{array}{l}\text { cN1-3 } \\
\text { M1a: } \\
\text { retroperitoneal } \\
\text { nodes }\end{array}$ & $\begin{array}{c}149 \\
(118 \\
\text { RC/PLND } \\
14 \text { HDRT })\end{array}$ & $\begin{array}{c}\text { MVAC / dd- } \\
\text { MVAC 62\% } \\
\text { CG / CarbG 38\% }\end{array}$ & RC/PLND & $\begin{array}{l}\text { Not defined but } \\
\text { did include pts } \\
\text { with SD }\end{array}$ & $\begin{array}{c}\text { Overall 5-year OS of } \\
29 \%\end{array}$ \\
\hline
\end{tabular}




\begin{tabular}{|c|c|c|c|c|}
\hline Study & $\begin{array}{c}\text { ClinicalTrials.gov } \\
\text { Identifier }\end{array}$ & $\begin{array}{c}\text { Disease } \\
\text { state }\end{array}$ & Treatment arms & $\begin{array}{c}\text { Estimated } \\
\text { completion } \\
\text { date }\end{array}$ \\
\hline Imvigor 130 & NCT02807636 & 1st line & $\begin{array}{c}\text { Atezolizumab vs. } \\
\text { Atezolizumab/platinum } \\
\text { based chemotherapy vs. } \\
\text { platinum based } \\
\text { chemotherapy }\end{array}$ & $\begin{array}{c}\text { November } \\
2020\end{array}$ \\
\hline Keynote 361 & NCT02853305 & $1^{\text {st }}$ line & $\begin{array}{c}\text { Pembrolizumab vs. } \\
\text { Pembrolizumab/platinum } \\
\text { based chemotherapy vs. } \\
\text { platinum based } \\
\text { chemotherapy }\end{array}$ & May 2020 \\
\hline Danube & NCT02516241 & $1^{\text {st }}$ line & $\begin{array}{c}\text { Durvalumab + } \\
\text { tremelimumab vs } \\
\text { durvalumab vs. standard } \\
\text { chemotherapy }\end{array}$ & $\begin{array}{l}\text { September } \\
2019\end{array}$ \\
\hline $\begin{array}{l}\text { Javelin } \\
\text { Bladder } 100\end{array}$ & NCT02603432 & $\begin{array}{c}\text { Maintenance } \\
\text { following } 1^{\text {st }} \\
\text { line }\end{array}$ & $\begin{array}{c}\text { Avelumab + BSC vs. BSC } \\
\text { alone }\end{array}$ & July 2020 \\
\hline $\begin{array}{l}\text { Checkmate } \\
901\end{array}$ & NCT03036098 & $1^{\text {st }}$ line & $\begin{array}{l}\text { Nivolumab/ipilimumab vs. } \\
\text { platinum-based } \\
\text { chemotherapy } \\
\text { Nivolumab/cisplatin } \\
\text { gemcitabine vs. cisplatin } \\
\text { gemcitabine alone }\end{array}$ & $\begin{array}{c}\text { December } \\
2022\end{array}$ \\
\hline
\end{tabular}

